\title{
Match-Fixing in Korean Football: Corruption in the K-League and the Importance of Maintaining Sporting Integrity
}

\author{
Graham Brooks \\ Institute of Criminal Justice Studies \\ University of Portsmouth, Portsmouth, United Kingdom \\ Julak Lee \\ Department of Protection \& Security Management \\ Kyonggi University, Suwon, Korea \\ Hakkyong Kim \\ Department of Police Administration \\ Keimyung University, Daegu, Korea
}

\begin{abstract}
Fraud and corruption is a problem that undermines the credibility and integrity of all sport. It affects fans, owners, shareholders, officials, and players. With the recent scandal in the K-League in Korea, the importance of maintaining the integrity of Korean football is presently of great importance. While other European or Asian football leagues have been plagued with fraud and corruption, Korea has maintained its professional sporting integrity successfully until recent times. This paper is an examination as to why players in the K-League succumbed to match-fixing in 2011. Firstly, we discuss the important role of sport in Korea, which is not to be underestimated. Secondly, we briefly illustrate the range and types of fraud and corruption in international football. Thirdly, we focus on the match-fixing and gambling scandal currently engulfing the K-League. Fourthly, we make some practical suggestions on how to combat and increase resilience to fraud and corruption in football. Finally, in the conclusion, we suggest that much needs to be done to reduce the incident of fraud and corruption in football worldwide, particularly through employing a clear counter fraud strategy.
\end{abstract}

Keywords: Football, Corruption, Match-Fixing, K-League, Gambling, Fraud

\section{INTRODUCTION}

With the recent vote rigging scandals in FIFA [40][2], and match-fixing in Germany [43] and also South east 'Asian' football involving players, officials, owners, and referees [23][24], the reputation of international football is perhaps understandably low. However, Korean football, until recently, has maintained its sporting integrity, and managed an 'honest' if not particularly profitable league, which has to compete with popular European and South America football for fans interests. A common theme of the match-fixing scandals around the world is the problem of legal and/or illegal gambling, depending on the jurisdiction. With the potential to 'win' substantial sums of money from match-fixing, it is seen as a worthwhile risk for players, officials, etc. For example, it

* Corresponding author, Email: julaklee@hanmail.net Manuscript received Feb. 09, 2012; revised May 28, 2012; accepted May 30, 2012 is suggested that one of the arrested 'brokers', in the Korean match-fixing scandal managed to secure 280 million won $\$ 255,000$ [35]. This paper then is primarily an examination of the recent scandal in Korea, but also draws on international examples of fraud and corruption in football, where relevant, and suggests that unless counter fraud strategies are employed, match-fixing will be a recurring problem that all football leagues, regardless of integrity, will encounter

Firstly, we highlight the importance of sport in Korea, and how it has been used by successive Presidents to provide legitimacy to military regimes, modernize Korea [30], promote Korean credentials on an international stage [27], and stimulate economic development and commercial success of 'Chaebol's, which refer to large family-controlled industrial conglomerates in Korea. This context is important, as many Chaebols now own football clubs in the K-League. Secondly, we illustrate the impact fraud and corruption can have on the integrity, and future financial success of sport. In addition to this, we highlight the different types of fraud and 
corruption that is found in international football, which are relevant to the K-League. Thirdly, there is an analysis of the match-fixing scandal in the K-League, and an attempt to explain the reason(s) behind the fraud and corruption. Where relevant, we draw on international examples of match-fixing as well, but primarily focus on the conditions in the $\mathrm{K}$ League and reason(s) why it has succumbed to match-fixing. Fourthly, we make some practical suggestions on how to combat and increase resilience to fraud and corruption in football. We draw on counter fraud strategies from private and public 'business sectors', and suggest that international football needs to protect itself from such scandals to maintain its integrity as a sport. Finally, in the conclusion, we suggest that much needs to be done to reduce the incident of fraud and corruption in football worldwide by using a tangible counter fraud strategy.

\section{THE IMPORTANT ROLE OF SPORT IN KOREA}

The role of sport in the Republic of Korea is not to be underestimated. Korea has, since it secured its freedom from Japan and survived the Korean War, used sport as a 'tool' to promote its credentials on an international stage [27]. This is however only part of the usefulness of sport; it can provide legitimacy to military regimes, increase international prestige and national pride, and stimulate economic and commercial success. These important roles that sport has and can play are not in order of importance. Instead of trying to put them in some sort of order, it is better to see sport as playing a collective social, political and cultural role. Football in Korea now, however, is more a commercial venture.

The Republic of Korea, particularly under the leadership of President Park, viewed sport as a tool to counteract a lack of political legitimacy and modernize Korea [30]. Even when hosting the Olympics in 1988 and under the leadership of President Chun, it has been suggested that the Seoul Olympics was an attempt to present the illusion of democratization while still under an authoritarian regime [31]. The Olympics were, regardless of the interpretation of 'Korean politics', a success; both in winning medals - Korea came fourth in the medal table in 1988 - and a much-needed stimulus for economic development.

It is not our intention here to dwell on the political development of the Republic of Korea; it is however our intention to highlight the role of sport as a mechanism of increasing international prestige, and how it can be damaged if seen as corrupt. It is however difficult to separate the manipulation of sport for political ends and the role of sport in a society. A brief look at the development of sport by successive regimes in Korea indicates the importance of sport; in 1954, the Ministry of Education increased physical exercise to three hours a week in middle and high schools to increase the physical fitness of the students [29]; the Korean Taekwondo Association was established in 1959; the National Sports Promotion Law was enacted in 1962, the Tae Neung Athletics Village was built in 1966 for elite athletes; the President's (Park's) Football Cup competition was launched in 1971; the Ministry of Sport was formed in 1982; the National Sports Promotion Law was revised in 1982; Korea held the Olympics in 1988, co-hosted the Football World Cup with Japan in 2002, and recently won the bid to hold the Winter Olympics in Pyeongchang in 2018 [27]. All of these developments helped established social order, material economic prosperity and political legitimacy and (for some) patriotism for successive Presidents of the Republic of Korea.

The value and importance of sport in Korea is therefore not of doubt. It has been used to present a regime as legitimate, increase its national pride on an international stage with success at the highest level, stimulate economic development, and increase the popularity of sport in Korea. It is suggested though that such success was a combination of state and Chaebol's vested interests [27]. Football teams are funded from the state Sports Toto, a sports lottery, and many Chaebols own professional football and baseball teams as well. Furthermore, heads of Chaebols run national sporting bodies and sponsor competitions. In the 1980s alone, of the 33 National Sporting organisations (NSO) in Korea, the heads of 25 of them were from Chaebols. The importance of sport to the Republic of Korea can also be seen in the amount of money spent by the Korean Sports Council (KSC), which increased from 12 billion Won in 1979 to 62.4 billion in 1985 , and in the establishment of professional baseball in 1982 and football in 1983 [42].

This rapid development, particularly of professional sport and established leagues, was also achieved by a combination of state and Chaebol's vested interests. For successive Presidents, sport was a 'tool' to secure political legitimacy as Korea slowly moved from military rule to a democratic country [22]; the Chaebols willingly followed state 'instructions' to help fund professional sports teams in exchange for 'favorable' contracts and tax 'breaks' to invest in sport. However, since the 1990s, Chaebols have been involved in sport in order to raise company profiles and associate sport with their brands and products rather than helping successive regimes due to the democratization in Korea. However, the change leaves sport in a vulnerable position; when the IMF crisis in 1997-98 hit Korea, sports became an unwanted cost for Chaebols they disbanded professional teams/sports e.g., 50 teams in 19 sports were cut. Now, with the integrity of the K-League in question, will the Sports Toto and Chaebols fund sport, which is associated with corruption?

Sport in the Republic of Korea then has developed, due to a number of factors. These are developing a national identity, particularly after the end of Japanese colonial rule and using sport as a method to build public morale and pride. It also helped manage the transition from a military to civilian democratic form of governing and hosted the Olympics, and Football World Cup, which created employment, and helped with the stimulation of urban renewal and the collective promotion of a nation. Nevertheless, these state and commercial successes are sometimes damaged if an individual or a sport is exposed as corrupt. This is the focus of the next section. 


\section{FRAUD AND CORRPUTION: AN INTERNATIONAL PROBLEM}

While definitions of fraud and corruption can differ, due to historical, cultural and legal developments, a broad approach to explaining them is that fraud is about deception and corruption is at times illegal, but also legal, but unethical [46]. These two however are intrinsically linked as "The distinction between corruption and fraud...is narrow" with an "international dimension for both" [14].

Attempting to define fraud and corruption, particularly across jurisdictions, is therefore a problem [1]; this however is only part of the problem. Even with a clear definition, which would be difficult, if not impossible, the measurement of fraud and corruption is also problematic [5]. Due to the secretive nature of fraud and corruption, it is difficult to police [45]. However, with the development of far more sophisticated measurement strategies now available [18][19][5], it is possible to put in place risk assessment exercises to reduce the incident of fraud and corruption, which international sporting bodies and individual clubs need to focus on to protect themselves from the range of frauds and corrupt acts that damage the integrity of sport, but also its financial capacity to function [20].

Few have really considered the world of football as a sector that is a victim of fraud and corruption, unless of course, it is match-fixing. This, however, is only one aspect of fraud that is found in football. While match-fixing attracts media interest, official and moral approbation, it is only one type of fraud that is committed in the world of football; below are a few examples of the potential for fraud and corruption in football in leagues around the world.

Ticket sales are perceived as the most important income stream for the financial performance of all football clubs [44]. Protecting this valuable income, regardless of the popularity of the league, is therefore of paramount importance. Football match tickets, as with all tickets for events can and are illegally manufactured and/or dispensed in return for business favors in the name of 'entertainment'. Tickets that are dispensed to officials and players for high profile international matches have been sold when they should not have been; in some cases, these tickets are sold for a substantial profit through a registered company [28]. Abuse of office, bribery and cronyism are part of the world of sport as much as politics and need to be recognized as such.

The purchase and wearing a football clubs colors is also popular, as is the purchase of sports apparel; the production of counterfeit items, such as football kits, posters, etc., also damage the income steam of a football club. All affect the profit margin in football and ultimately a football clubs ability to survive and maintain its status as a club, and pay for star players. This is especially the case for those leagues, such as the K-League in Korea, which is competing with baseball. If not careful, the important commercial sponsorship that is needed to maintain a sport will be withdrawn and seek alternative sports with which to be associated.

Furthermore, money laundering is nothing new to world football. There are cases of laundering money using the sale and purchase of players, major building projects, and tax evasion in European jurisdictions [16]. Footballers are bought and sold for a set price, but not always in public. The actual fee paid can be different to that quoted, as 'extra' money is paid in cash to the selling club; this could be to the manager, player, owner(s) and/or agent(s). Such 'extra' money is difficult to trace, particularly if funds are paid into offshore accounts. In some cases, it is difficult to determine who the actual owners of a football club are [12]. In addition, players in European leagues have been bought and sold between clubs for vast sums of money that never play for either football team in any competition. Such players are often over-valued and payment into offshore bank accounts is made, which are difficult to discover and assess [16]. This paper is not suggesting that such acts of fraud and corruption have occur in the K-League, it is however suggesting that awareness is needed and counter fraud strategies developed, as match-fixing is only one way a sport is a potential victim of fraud and corruption [20].

The above examples could lead to tax avoidance and/or evasion as well. This could be with tacit approval, knowledge of football club owners, major shareholders, managers, and players. This type of fraud though is one that benefits 'football' or those involved in football; it is however fraud, and as such needs to be dealt with to protect the integrity of the sport. However, it is the match-fixing scandals and the people involved in football that damages the integrity of sport more than most examples of fraud and corruption. This is perhaps because it is defrauds all of an honest spectacle, the paying fans, the officials running the league, the owners of football clubs, and damages the integrity of all associated with the sport [8].

In the next section, we examine the reason(s) why some KLeague players decided to fix football matches and accept bribes rather than play with integrity and damage the reputation of Korean Sport and the K-League.

\section{A CASE OF MATCH-FIXING IN FOOTBALL \& DAMAGE TO KOREAN SPORTING INTEGRITY}

While sport in the Republic of Korea developed under a succession of military dictatorships and personal 'favored' economic conditions for some individuals and Chaebols, it was successful at international sporting events and developing national leagues [27]. However, with the recent match-fixing scandal and corruption in the K-League in 2011, the sport of football, along with those whose sponsor it, is damaged.

It is often thought that players are only those involved in match-fixing; this is incorrect. Players are needed to fix a match, but not always. Referees, club officials, owners, and players have all been involved. In some international matches, players have conspired to lose to win cash and/gifts by fixing the result of a football match [24]. By losing the match, scoring the right amount of goals, missing a penalty, getting booked and/or sent off the field of play have all help secure extra illegal payments [8]. It is where players and referees that have conspired to fix a football match to receive illegal 
payments that most damage the integrity of the sport, and it is this fix that deprives the fans of a real sporting event, regardless of the level at which it is played.

The match-fixing scandal in football in Korea then is nothing new in an international context; it is however unusual for the K-League in Korea. We briefly review the recent match-fixing scandal in the K-League here, as it appeared in the beginning that it is more than a few wayward corrupt players were involved in the scandal. However, in the end, a total of 46 footballers and 11 others, including brokers and financiers, have been indicted, and among them, 40 football players were expelled permanently from the K-League. Also, the dividend of the clubs where the footballers belonged to was reduced, for example, Daejeon Citizen's dividend of Sports Toto was reduced 30 per cent for 2011 season, and Gwangju FC and Sangju Sangmu Phoenix was reduced 10 per cent each [32][33].

It is alleged that the players attempted to fix a match when playing Pohang Steelers on April 2011 in a cup match; Daejeon Citizen lost the match 3-0 and one player from the Pohang Steelers was indicted after placing a bet on his own team after receiving information of the fix from a Daejeon Citizen Player. The main accusations however are that players accepted money from betting organizations to fix specific results in selected matches, rather than one match, and it is thought that bets of 1 billion won $(\$ 928,000)$ were sometimes placed on single matches. The extent of matchfixing is therefore unknown and the level of corruption is difficult to assess.

The K-League Cup is an 'auxiliary' competition held on weekdays (similar to League Cup in England). The reason(s) put forward for the match-fixing are that this competition attracts little interest, and teams' field weakened sides playing reserve players that are 'seduced' into fixing to supplement low incomes. There is some evidence that football matches around the world are fixed in lower leagues and less important cup competitions, but also at the European and international level as well [16][24][43]. If anything then, with the widespread corruption in football, it is surprising that this is the first case of match-fixing in the K- League that we are aware of.

As with other frauds elsewhere [7][14][21][37], the reason(s) put forward for match-fixing are that professional athletes have a brief sporting career and will sometimes succumb to match-fixing to 'earn' extra money. Players, in all sports, justify these acts as bending the rules, rather than corruption, explaining that the match in question was insignificant and that everybody is involved and that such fraud and corruption is 'common practice'.

With many leagues in Asia, football is very popular in Korea but the domestic league is seen as poor, particularly in comparison to the European and South America leagues. As a consequence of the match-fixing scandal, attendances, which were already modest at K-League matches, has dwindled. Unless such corruption is dealt with, this recent match-fixing scandal, like elsewhere in international football, will occur again [16][23][24]. It is to methods of prevention that we now turn, and make desirable recommendations on how best to reduce the incident of fraud and corruption in football.

\section{METHODS OF PREVENTION: A COUNTER FRAUD STRATEGY}

There are key elements to any counter fraud strategy, regardless of the focus of its business, and these are well documented, to name a few [4][9][25][38][17][26][15][34]. The world of sport is no different to other business sectors, as it will experience some of the frauds mentioned earlier in this paper, but it will also suffer from frauds that are particular to it such as match-fixing.

The suggestions below are therefore key elements to counter fraud and corruption regardless of the business sector, with some specific to football. It is heartening to see that the Korean Football Association (KFA) has already decided that those players involved in the K-League scandal will do all it can to prevent them from having any role in Korean football or similar position [33]. Furthermore, the KFA also imposed penalties on the players' teams and for instance, as mentioned earlier, Daejeon Citizen will lose 30 per cent of its share of the Sports Toto, which professional teams receive from the sale of lottery ticket sales. These sanctions however are a reaction to the problem rather than a solution.

To reduce the incident of all fraud and corruption in football, a clear counter fraud strategy is needed. There are numerous articles explaining and highlighting the key elements of a counter fraud strategy [9][4][10][7], and we review each key element below, and make practical suggestions on how these should be applied to prevent a potential match-fixing scandal in the K-League in the future.

This 'strategic list' of key elements is not exhaustive. It is however underpinned by a growing body of work [4][9]. From this body of work, an effective counter fraud strategy has rapidly developed. Building on previous literature, the following elements form the platform upon which we can perhaps claim to have a model counter fraud strategy: These elements are:

- The possession of a counter fraud strategy,

- $\quad$ Employment of or access to professionally trained counter fraud specialists,

- Pursuit of civil and criminal sanctions,

- Pursuit of financial redress,

- Designating a person with responsibility for counter fraud strategy,

- Anti-Fraud Culture Strategies such as fraud awareness training,

- Independent whistle blowing mechanisms,

- Measurement of fraud on a regular basis, including evaluation of counter fraud strategies.

All organizations should have a clear counter fraud strategy; this is where it openly states its intent to prevent fraud and corruption and have an explicit approach in countering fraud and threats to its integrity. A clear counter fraud strategy will signify to its own employees and external contracted employees or 'gambling brokers' that it will do all it can to maintain the integrity of its sport and dismiss internal employees involved in fraud and corruption, seek 
financial redress for money stolen, and use the panoply of civil and criminal sanctions available, depending on the jurisdiction.

For this approach to be effective, an organization wanting to reduce and prevent the incidence of fraud and corruption should employ a counter fraud specialist. A clear designated person whose remit is to deal with counter fraud issues is an essential element of a successful counter fraud strategy. After all, with a clear remit and knowledge of fraud, such a person could be a conduit to broadcast fraud issues in a company and raise awareness, prevent fraud, develop an anti-fraud strategy and culture, work and liaise with law enforcement bodies, and if required, produce a report for the company board [9].

Developing an anti-fraud culture is considered as a major part of a preventative strategy [9][10]. One of the tools used to achieve this is the education and instruction of employees in identifying and preventing fraud. The nature and approach taken in developing an anti-fraud culture however is varied. For example, in some organisations, all new employees are made aware of the threat of fraud as part of employee induction. In other instances, employees attend fraud conferences, update knowledge and understanding of fraud online or commission specific fraud packages relevant to an organization's business [4][9]. Furthermore, an organization can use its own intranet to disseminate information regarding fraud, hold fraud risk workshops to identify fraud risks and detail actions needed to counteract them, and produce specific whistle blowing procedures. The development of an anti-fraud culture encouraging reporting of fraud and corruption in the form of whistle blowing, which has been introduced in some sectors e.g., police [41], is needed, if corruption in football is to be controlled. While we are aware that it is impossible for every company to pre-determine every type of fraud it might encounter, regardless of its 'business', it must be aware that certain areas of its 'business' are vulnerable to fraud more than others, and that the assessment of risk is an integral part of developing an antifraud strategy and anti-fraud culture.

Part of this strategy is to also interview, seek reference checks, credit checks and request original documentation such as qualifications for employees as well. However, as we know these can be circumvented, but of far more importance is the on-going risk assessment of all those employed by the clubs. As with every business, those on the 'inside,' can and often commit fraud [21]. Those 'internal' employees who are familiar with the organization, its practices, and methods of operation that are seduced by outside influence, as the football players of Daejeon Citizen were, are open to fraud and corruption. As suggested elsewhere, the same vigilance should apply regarding fraud risk assessment regardless of the 'employees' contractual position; fraud risk assessment should be an ongoing exercise if the level of fraud is to be reduced [4].

Furthermore, an independent whistle blowing process is an important part of developing an anti-fraud culture and prevention and detection of potential frauds. Reporting fraud or anything that might come under the vague category of suspicious activity could be separated into external and internal risk of fraud. While the reporting of external fraud is perhaps approached with more vigor that internal fraud, it is perhaps here, if left unchecked that fraud is able to damage the sport in a way that external fraud is limited.

While we would expect a company to have some type of whistle blowing procedure in place, where employees can raise their concern regarding other employees, the reality and experience for some whistleblowers is one where employers and also professional colleagues question the whistleblowers motives and integrity, and also target them for verbal abuse, demotion, termination of employment and ultimately threats of physical harm and violence [39]. The toll on a person(s) and their family is, and can be overwhelming. To inform openly or even anonymously on a colleague is a serious matter and one that is in need of further research.

These elements of a model strategy should not be viewed as a 'pick and mix' type approach where some elements are of use more than others; it is the sum of parts, when employed in combination which have the potential to prevent, reduce, and hopefully deter those out to commit fraud. No organisation should be satisfied with a strategy that exists on paper, or one that is dependent on anonymous hotlines. Since fraud is such a complex issue, particularly when involved with sport, it is essential and of paramount importance, if an organisation regards fraud as a serious issue, that it develops a robust strategy.

Due to the system of criminal justice in Korea where the prosecutors possess the power to continue or discontinue with a case, some of these suggestions might be regarded as irrelevant to the KFA. However, as the body directly in charge of maintaining the integrity of football in Korea, and by implication its own integrity as many matches appeared to have been fixed, it needs a clear counter fraud strategy to protect its own integrity and prevent rather than react and punish offenders after the event, as the damage to Korean football has already occurred.

Finally, the pursuit of civil and criminal sanctions and financial redress are important elements of a strategy. Withdrawing Sports Toto funds is a start, but as was mentioned earlier, the damage to commercial success, as fans stay away from the stadium with Chaebols perhaps seeking other sports with which to be associated, could do more than ruin the integrity of the K-League, it could damage the entire $\mathrm{K}$-league beyond repair as capital is invested elsewhere.

\section{CONCLUSION}

Any organization that takes fraud seriously and has been in the process of developing a counter fraud strategy is to be commended. However, the development of an anti-fraud culture is of limited value if employees have no clear direction as to what fraud is, or might possibly emerge. A codified set of guidelines regarding fraud, ethical behavior, a set code of conduct, response plan(s) and anti-fraud policies alone are insufficient. If they fail to educate and hold those who ignore, break or circumvent 'codes of conduct' accountable, then the attitude to fraud is unlikely to change. After all, as Ernest and Young noted [15], Enron Corporation 
had a code of ethics and a whistleblower mechanism, and yet, neither worked. A strategy needs direction, clear codes of conduct, which need to be enforced if it has any chance of success. Issuing a counter fraud policy is the start of a counter fraud strategy it is not an end in itself.

Therefore, an effective strategy should contain a designated person(s) whose remit is to deal with counter fraud issues, ongoing risk assessments, and promote an active anti-fraud culture with a clear process and procedure in which all employees are confident of reporting fraud without fear of reprisals. Furthermore, and this is an indispensable part of any strategy; employers must utilize relevant and available sanctions, depending on the fraud committed, whether the person is an internal employee or under temporary contract or working for another company. After all, the threat of any sanction is of little use if that threat is not feared, used and brought to bear on those that commit fraud; similar to a counter fraud strategy it has to be more than a 'paper threat,' it has to be real and employed when the fraudulent act is of such a magnitude that the case should reach a criminal court [4].

Sport in Korea of is a source of national and international pride [27]. Both the state and 'big business' have worked together to raise the standard and profile of Korea as a nation of sporting excellence [22]. In some sports Korea has achieved at the highest level e.g., ice skating, Taekwondo to name a few and hosted the most prestigious sporting tournaments in the world. It has, in the world of sport, mostly been free of fraud and corruption. In the world of football, until recently, it was not conceived as corrupt, as the KLeague did not suffer from the same scandals other football leagues in South East Asia has experienced. To maintain its sporting integrity though, the KFA, the players, officials and owners of football teams need to do more than ban those involved in the match-fixing. Prevention is necessary and counter fraud measures need to be put in place if the KLeague is to retain the sporting integrity it once possessed and attract fans and sponsorship to football in Korea.

\section{REFERENCES}

[1] J. Bhagwati, "Defining corruption", JoongAng Daily, Friday, December 31 2010, p. 9.

[2] R. Blitz, "FIFA clears Blatter of approving bribes to voters", Financial Times, Monday, May 30 2011, p. 30.

[3] CIFAS, The Internal Betrayal: A CIFAS report on beating the growing threat of Staff Fraud, CIFAS, London, 2009.

[4] G. Brooks, M. Button, and K. Frimpong, "Policing fraud in the private sector: a survey of the FTSE 100 companies in the UK", International Journal of Police Science and Management, vol. 11, no. 4, 2009, pp. 493504.

[5] G. Brooks, M. Button, and J. Gee, "The Scale of Healthcare Fraud: A Global Evaluation", Security Journal, vol. 25, no. 1, 2011, pp. 76-87.

[6] G. Brooks, M. Button, and A. Azeem, Fraud and Corruption in Sport, Palgrave McMillan, Basingstoke,
2012.

[7] G. Brooks and M. Button, "The Police, Fraud, and the Case for a Nationalized Solution in the United Kingdom”, The Police Journal, 2012 (available online).

[8] G. Brooks, "Challenging the myth of urban regeneration: Raising the profile of problem gambling with a media campaign", Journal of Gambling Studies, 2012,

Available:http://www.springerlink.com/content/v553m 308x6477528/ [accessed 1 February 2012].

[9] M. Button and G. Brooks, "Mind the Gap: Progress towards developing anti-fraud culture strategies in UK Central Government Bodies", Journal of Financial Crime, vol. 16, no. 3, 2009, pp. 229-244.

[10] M. Button, G. Brooks, and J. Gee, "Measuring the Cost of Fraud: An Opportunity for the New Competitive Advantage", Journal of Financial Crime, vol. 19, no. 1, 2012, pp. 65-75.

[11] S. Choe, "46 Players Are Indicted in South Korea Scandal", The New York Times, Thursday, July 72011 , Available:http://www.nytimes.com/2011/07/08/sports/s occer/08iht-soccer08.html [accessed 2 February 2012].

[12] Christian Aid, Blowing The Whistle: Time's Up For Financial Secrecy, Christian Aid, UK, 2010.

[13] B. Cummings, Civil Society in West and East, In C. K. Armstrong (Ed), Korean Society; Civil Democracy and the State, Routledge, London, 2002, p. 118.

[14] A. Doig, Fraud, Willan Publishing, Cullumpton, 2006.

[15] Ernst \& Young, 9th Global Fraud Survey, Ernst \& Young, South Africa, 2006.

[16] J. Foot, Calcio: a history of Italian football, Harper Perennial, London, 2007.

[17] Fraud Review Team, Final Report, The Legal Secretariat to the Law Officers, London, 2006.

[18] J. Gee, M. Button, and G. Brooks, The Financial Cost of Fraud, MacIntyre Hudson, Milton Keynes, 2009.

[19] J. Gee, M. Button, and G. Brooks, The financial cost of UK Public Sector Fraud: A less painful way to reduce public expenditure, MacIntyre Hudson, Milton Keynes, 2010.

[20] J. Gee, G. Brooks and M. Button, Fraud in Football: Research into how well football protects itself against fraud, PKF, London, 2011.

[21] D. Gill, Learning from fraudsters, Protiviti Group, London, 2005.

[22] N. Ha and J. A. Mangan, "Ideology, Politics, Power: Korean Sport-transformation, 1945-92", International Journal of the History of Sport, vol. 19, No. 2, 2002, pp. 213-242.

[23] D. Hill, The Fix: Soccer and Organized Crime, McClelland and Stewart, Toronto, 2008.

[24] D. Hill, Strategies of Corruption: How Corrupt Football Players and Referees Perform Fixed Matches, In M. Kreutner (Ed), Practice Meets Science Contemporary Anti-Corruption Dialogue: IACSS 2009, Manz Crossmedia, Vienna, 2010.

[25] HM Treasury, Managing the Risk of Fraud: A Guide for Managers, HM Treasury, London, 2003.

[26] Home Office, The Fraud Act 2006, Home Office, 
London, 2006.

[27] E. Hong, "Elite Sport and Nation-Building in South Korea: South Korea as the Dark Horse in Global Elite Sport", International Journal of the History of Sport, vol. 28, no. 7, 2011, pp. 977-989.

[28] A. Jennings, Foul! The Secret World of FIFA: Bribes, Vote Rigging and Ticket Scandals, Harper Collins, London, 2007.

[29] S. W. Kang, The Political Economy of Korean Education, Hankilsa, Seoul, 1990.

[30] M. Kim, "Modernizing effects on Sports and Physical Activities Among Korean Adults", International Review for the Sociology of Sport, vol. 31, no. 2, 1996, pp. 155-172.

[31] Y. W. Kihl, Transforming Korean Politics: Democracy, Reform and Culture, M.E. Sharpe, New York, 2005.

[32] Korean Herald, "Prosecutors indict key figures in football match-fixing", The Korean Herald, Friday, June 10 2011, p. 20.

[33] Korean Times, "K-League issues lifetime ban on footballers for match-fixing", The Korean Times, Saturday/Sunday, June 18-19 2011, p. 20.

[34] KPMG, Profile of a fraudster, KPMG, London, 2007.

[35] H. S. Lee, "Key figures indicted in game-fixing scam", The Korean Times, Friday, June 10 2011, p. 3.

[36] Y. H. Lee, The State, Society and Big Business in South Korea, Routledge, London, 1997.

[37] M. Levi, Fraud: Organization, Motivation and Control, Ashgate, Aldershot, 1999.

[38] National Audit Office and HM Treasury, Good Practice in Tackling External Fraud, National Audit Office, London, 2004.

[39] L. T. Nichols, "Whistleblower or renegade?: Definitional contest in an Official Inquiry", Symbolic Interaction, vol. 14, no. 4, 1991, pp. 395-414.

[40] A. O'Connor, "FIFA executive committee pair banned after investigation into corruption", The Times, Friday, November 19 2010, p. 14.

[41] H. Park and J. Blenkinsopp, "Whistle blowing as planned behaviour - A survey of South Korean police officers", Journal of Business Ethics, vol. 85, no. 4, 2009, pp. 545-556.

[42] Y. O. Park, "The Political Economy of Sport: The Shift of Political Paradigm and Sport", Sports Science, vol. 59, no. 1, 1997, pp. 4-13.

[43] E. Pfanner, "Corruption scars the playing fields of Europe", International Herald Tribune, SaturdaySunday, January 8-9 2011, p. 16.

[44] PKF, The annual survey of football club finance directors 2010, PKF, London, 2010.

[45] W. Sandholtz and M. Gray, "International Integration and National Corruption", International Organization, Vol. 57, no. 4, 2003, pp. 761-800.

[46] Transparency International, Corruption in the UK: Overview and Policy Recommendations, Transparency International, UK, 2010.

[47] S. Wade and B. S. Kim, Economic Development of South Korea: The Political Economy of Success, Praeger, New York, 1978.

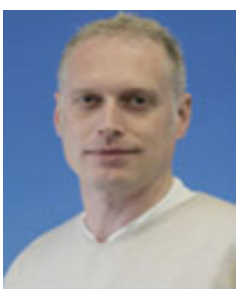

\section{Graham Brook}

$\mathrm{He}$ is a senior lecturer at the Institute of Criminal Justice Studies at the University of Portsmouth, UK. His areas of expertise are fraud and corruption, community safety and crime prevention, youth justice and gambling addiction. He obtained his MPhil degree in Criminology from Cambridge University, UK.

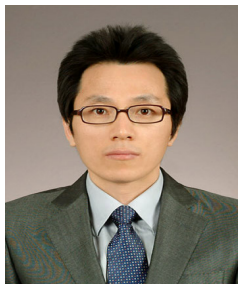

\section{Julak Lee}

$\mathrm{He}$ is an assistant professor of the department of protection and security management at Kyonggi University in Korea. He obtained Master's degree from the Michigan State University, US, majoring in Criminal Justice, and earned $\mathrm{PhD}$ in Criminal Justice from the University of Portsmouth, UK.

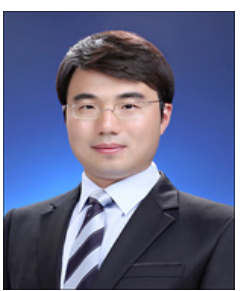

Hakkyong Kim

$\mathrm{He}$ is a full-time lecturer of the department of police administration at Keimyung University in Korea. He earned his MSc degree in Risk, Crisis \& Disaster Management from the University of Leicester, UK. In May 2011, he obtained his PhD in Risk \& Crisis Management at the University of Portsmouth, UK. 